\title{
Computed tomography features of traumatic pulmonary pseudocysts
}

\author{
Onur Taydaş ${ }^{1} \odot$, Burak Gümüşs²๑, Erdal $\operatorname{Karavaş}^{1} \odot$ \\ ${ }^{1}$ Department of Radiology, Erzincan University Mengücek Gazi Training and Research Hospital, Erzincan, Turkey \\ ${ }^{2}$ Department of Forensic Medicine, Erzincan University Mengücek Gazi Training and Research Hospital, Erzincan, Turkey
}

DOI: $10.18621 /$ eurj.420468

\begin{abstract}
Objectives: To discuss the radiological characteristics of traumatic pulmonary pseudocyst (TPP) detected by thorax computed tomography.

Methods: Retrospective screening was made of 107 patients applied with thorax computed tomography due to blunt thoracic trauma between 2014 and 2017 at our hospital.

Results: TPP was detected in $6(5.6 \%)$ patients. The patients comprised 5 males and 1 female with a mean age of 28 years (range, 15-49 years). Blunt thorax trauma was caused by traffic accidents in 4 patients and a fall from height in 2 patients. Eleven (64.7\%) of the lesions were located in the lower lobes. The most common finding associated with TPP was ground glass opacities, which were present in all of the patients and represented the parenchymal contusion.

Conclusion: Thorax computed tomography is an effective and reliable method for early and definitive diagnosis of the rare development of TPP after blunt thoracic trauma.
\end{abstract}

Keywords: traumatic pulmonary pseudocyst, blunt chest trauma, computed tomography

Received: May 2, 2018; Accepted: June 23, 2018; Published Online: August 9, 2018

$\mathbf{P}$ ulmonary parenchymal injuries after blunt thoracic trauma vary from simple contusion to laceration. Traumatic pulmonary pseudocyst (TPP) is a rare complication of blunt chest trauma. It is a type of cavitary lesion that occurs in the lung parenchyma as a result of air leakage from the cleft caused by forces tearing the lung parenchyma. It constitutes $2.6-3 \%$ of parenchymal injuries after blunt thorax trauma [1]. TPP usually develops in children and young people and is characterized by the absence of a distinct epithelial wall within the cyst. These lesions are often asymptomatic and incidentally detected. Although computed tomography $(\mathrm{CT})$ has an important role in diagnosis [2], there are very few studies in literature that have discussed the CT features of pseudocysts and they are mostly case reports.

The aim of this study was to discuss the radiological characteristics of TPP detected by thorax CT. in 6 patients.

\section{METHODS}

A total of 107 patients applied with thoracic CT due to blunt thoracic trauma between 2014 and 2017 were screened retrospectively. TPP was detected in 6 (5.6\%) patients. The patients comprised 5 males and 1 female with a mean age of 28 years (range, 15-49

Address for correspondence: Onur Taydaş, MD., Erzincan University Mengücek Gazi Training and Research Hospital, Department of Radiology, Erzincan, Turkey

E-mail: taydasonur@gmail.com,Tel: +90-446-212-2213 
Table 1. Demographic data and CT findings

\begin{tabular}{|c|c|c|c|c|c|}
\hline Patients & $\begin{array}{l}\text { Gender and } \\
\text { age (years) }\end{array}$ & $\begin{array}{l}\text { Cause of } \\
\text { trauma }\end{array}$ & $\begin{array}{l}\text { Number of } \\
\text { pseudocysts }\end{array}$ & $\begin{array}{c}\text { Lobar } \\
\text { Distribution }\end{array}$ & Associated Findings \\
\hline 1. GD & $\begin{array}{l}\text { Male } \\
30 \mathrm{y}\end{array}$ & $\begin{array}{c}\text { Fall from } \\
\text { height }\end{array}$ & 6 & $\begin{array}{l}\text { Right lower lobe } \\
\qquad(\mathrm{n}=6)\end{array}$ & $\begin{array}{c}\text { Hemothorax } \\
\text { Pneumothorax } \\
\text { Subcutaneous emphysema } \\
\text { Rib fractures } \\
\text { Ground glass opacities }\end{array}$ \\
\hline 2. DY & $\begin{array}{c}\text { Female } \\
43 \mathrm{y}\end{array}$ & $\begin{array}{l}\text { Traffic } \\
\text { accident }\end{array}$ & 2 & $\begin{array}{l}\text { Left lower lobe } \\
\qquad(\mathrm{n}=2)\end{array}$ & $\begin{array}{l}\text { Rib fractures } \\
\text { Ground glass opacities }\end{array}$ \\
\hline 3. FA & $\begin{array}{l}\text { Male } \\
17 \mathrm{y}\end{array}$ & $\begin{array}{l}\text { Traffic } \\
\text { accident }\end{array}$ & 1 & $\begin{array}{l}\text { Left lower lobe } \\
\qquad(\mathrm{n}=1)\end{array}$ & Ground glass opacities \\
\hline 4. Sİ & $\begin{array}{l}\text { Male } \\
26 \mathrm{y}\end{array}$ & $\begin{array}{l}\text { Fall from } \\
\text { height }\end{array}$ & 5 & $\begin{array}{l}\text { Left upper lobe } \\
\qquad(\mathrm{n}=5)\end{array}$ & $\begin{array}{l}\text { Rib fractures } \\
\text { Ground glass opacities }\end{array}$ \\
\hline 5. TT & $\begin{array}{l}\text { Male } \\
21 \mathrm{y}\end{array}$ & $\begin{array}{c}\text { Traffic } \\
\text { accident }\end{array}$ & 2 & $\begin{array}{l}\text { Left lower lobe } \\
\qquad(\mathrm{n}=2)\end{array}$ & Ground glass opacities \\
\hline 6. YKO & $\begin{array}{l}\text { Male } \\
15 \mathrm{y}\end{array}$ & $\begin{array}{l}\text { Traffic } \\
\text { accident }\end{array}$ & 1 & $\begin{array}{l}\text { Left upper lobe } \\
\qquad(\mathrm{n}=1)\end{array}$ & $\begin{array}{c}\text { Pneumothorax } \\
\text { Ground glass opacities } \\
\text { Traumatic subarachnoid } \\
\text { hemorrhage }\end{array}$ \\
\hline
\end{tabular}

years). CT scans were performed with a 16-slice CT scanner (Sensation 16, Siemens Medical Systems, Germany) using $100 \mathrm{ml}$ of intravenous (IV) contrast material (300 mg/ml Omnipaque, GE Healthcare, Ireland) at a flow rate of $4 \mathrm{ml} / \mathrm{sec}$. No oral contrast material was given. The thorax CT scans (tube voltage $=120 \mathrm{kV}$, effective $\mathrm{mAs}=90$, slice thickness $5 \mathrm{~mm}$, collimation $=2 \times 4 \mathrm{~mm}$, pitch $=1.6$ ) were acquired 40 seconds after the IV contrast injection. The images were retrospectively reviewed by 2 radiologists, one with 10 years of experience and the other with 5 years of experience. There was agreement between them for each case.

\section{RESULTS}

The patients with TPC detected on CT comprised 5 males and 1 female with a mean age of $25.5 \pm 10.1$ years (range, 15-43 years). The CT findings of the patients are summarized in Table 1. Blunt thorax trauma was caused by traffic accidents in 4 patients

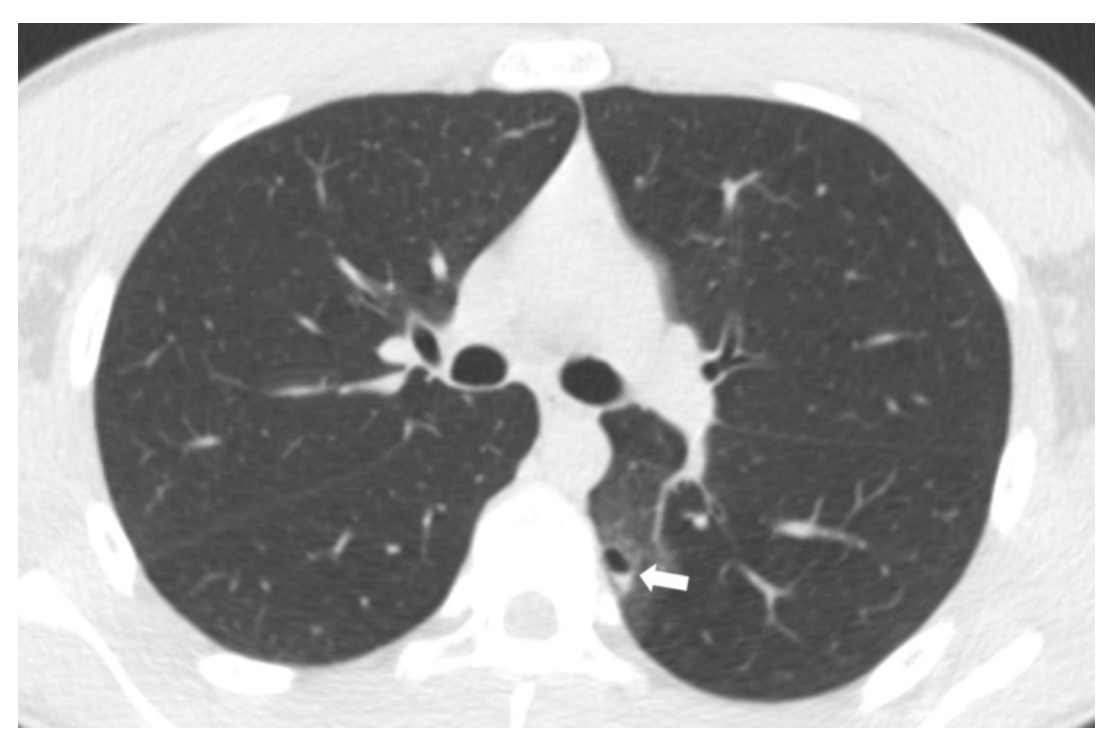

Figure 1. A 17-year-old male with blunt thoracic trauma after a traffic accident. Axial CT image showing traumatic pulmonary pseudocyst with air-fluid level (white arrow). 


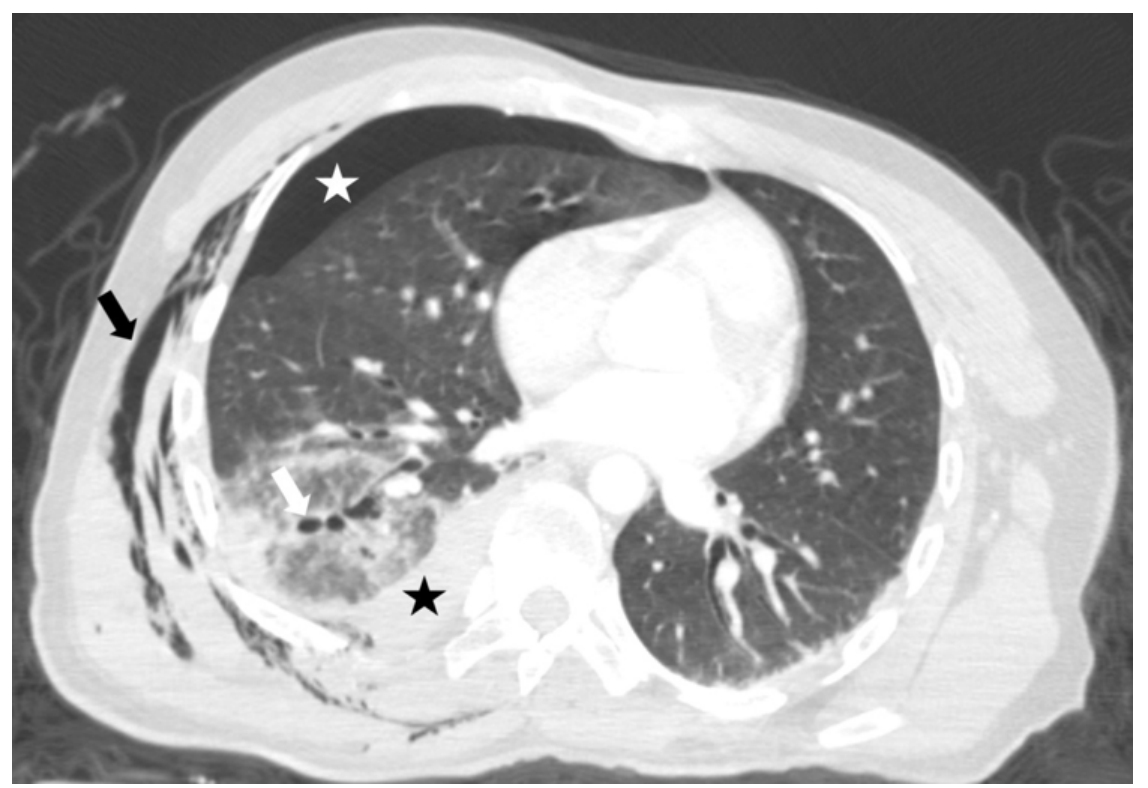

Figure 2. A 30-year-old male with blunt thoracic trauma after a fall from height. Axial CT image showing traumatic pulmonary pseudocyst (white arrow), subcutaneous emphysema (black arrow), pneumothorax (white asterisk) and hemothorax (black asterisk).

and a fallfrom height in 2 patients. All the patients had CT scans at the time of admission to hospital. A total of 17 lesions were detected in 6 patients. The mean number of lesions was 2.8 (range, 1-6), with $6(35.3 \%)$ detected in the right lobe and $11(64.7 \%)$ in the left lobe. There were $6(35.3 \%)$ lesions in the right lower lobe, $5(29.4 \%)$ lesions in the left lower lobe, and 6 $(35.3 \%)$ lesions in the upper left lobe. In total, 11 $(64.7 \%)$ of the lesions were located in the lower lobes, $8(47.1 \%)$ lesions were subpleural and $9(52.9 \%)$ lesions were intraparenchymal. There were air fluid levels in 4 (23.5\%) of the lesions (Figure 1).

The most common finding associated with TPP was ground glass opacities, which were present in all of the patients and represented the parenchymal contusion. The second most common finding was rib fracture in 4 patients. One patient had pneumothorax and one patient had hemopneumothorax and subcutaneous emphysema (Figure 2). One patient had traumatic subarachnoid hemorrhage in addition to lung findings.

\section{DISCUSSION}

In this study, TPP was detected in $5.6 \%$ of the patients with blunt thoracic trauma. In literature, this ratio is reported as $2-3 \%$ in older studies [2-4] and 5-
$10 \%$ in more recent studies [5-8]. Cho et al. [7] attributed this to the increased use of CT on blunt thoracic trauma patients.

TPPs are cavitary lesions that can occur after blunt thoracic trauma. Two mechanisms have been proposed in TPP formation. The first is that an area of the lung is occluded by a sudden compression of a segment of the peripheral bronchial tree and the pressure created causes it to split in this closed area. The enclosed space then expands with the rupture of the alveolar walls. The second possible mechanism is explained by the production of concussion waves that create rippling forces that tear the lung parenchyma [9]. This complication is more common in children and young adults because the elastic structure of the chest wall causes a large part of the traumatic energy to be transferred to the lung parenchyma. It has been reported that $75-85 \%$ of the patients are males aged $<$ 30 years [3]. Similarly, in the current study, 5 of the 6 patients were male and the mean age was $25.5 \pm 10.1$ years.

Traumatic pulmonary pseudocysts are usually oval or round in shape and are seen in the lower lobes [3]. In the current study, $64.8 \%$ of the lesions were located in the lower lobe. Plain chest radiographs are not suitable for TPP imagingbecause these lesions can be concealed by opacities formed by pulmonary contusion. In addition, incomplete formation of 
pseudocysts in the early period after trauma is difficult to recognize with radiography [2]. In areview of 7 large series by Tsitouridis et al. [6], the sensitivity of chest radiography was found to be only $24 \%$ in the early period. In contrast, CT can easily detect pseudocysts as thin-walled cysts in the lung parenchyma. In some of these cysts, air-fluid level can be seen associated with blood arising from peripheral pulmonary vessels or alveolar capillary vessels [3]. In 4 of the pseudocysts of the current study, air-fluid levels were observed. The most common finding associated with pseudocysts is "ground glass" opacities representing parenchymal contusion. In a study of 5 patients by Tsitouridis et al. [6], all had parenchymal opacities. Similarly, in the current study, parenchymal opacities were present in all patients.

It is important to determine whether cystic lesions that are observed radiologically in TPP cases are preexisting cystic structures. Other pathologies with cavitary lesions in the differential diagnosis should be kept in mind. In adults, these include blister, bleb, lung abscess, bronchial carcinoma, bronchogenic cyst, pulmonary infarction, tuberculosis, cyst hydatid and coccidoidomycosis, whereas in children, congenital pulmonary cysts and pulmonary sequestration are similar to traumatic pseudocysts. The history of trauma in the patient and the radiological change of the lesion over time suggest TPP, but if lesions do not show improvement in long-term follow-up,other pathologies should be considered in the differential diagnosis [1].

Although TPPs may be clinically asymptomatic, the most common symptoms are hemoptysis, chest pain and cough. However, these symptoms are not only related to the TPP itself, but also to other concomitant parenchymal injuries, especially pulmonary contusion. These lesions have a benign clinical course, and often do not require specific treatment [4]. Typically, any treatment applied is diagnostic and surgical treatment should not be considered unless complications develop such as infection, bronchial hemorrhage or rupture of the pleural space. Hemoptysis is not usuallylifethreatening and does not require surgical treatment [10]. However, to control bronchial hemorrhage, some cases requiring lobectomy have been reported. Pseudocysts are rarely complicated by infection. None of the patients in the current study had any complications and therefore no surgical intervention was required.

\section{Limitations}

This study had several limitations. First, the nature of the study was retrospective. Second, since the patients were not followed up in the long term, no data could be presented about the healing process. Finally, the study had a relatively small sample size, so no statistical analyses could be applied.

\section{CONCLUSION}

In conclusion, thorax $\mathrm{CT}$ is an effective and reliable method for early and definitive diagnosis of TPP, which is an uncommon development after blunt thoracic trauma.

\section{Author contributions}

Concept - O.T., B.G., E.K.; Design - O.T., E.K.; Supervision - B.G., E.K.; Resource - O.T., B.G., E.K.; Materials - O.T., E.K.; Data Collection and/or Processing - B.G., E.K.; Analysis and/or Interpretation - O.T., B.G., E.K.; Literature Search - O.T., E.K.; Writing - O.T., B.G., E.K.; Critical Reviews - O.T., B.G., E.K.

\section{Conflict of interest}

The authors disclosed no conflict of interest during the preparation or publication of this manuscript.

\section{Financing}

The authors disclosed that they did not receive any grant during conduction or writing of this study.

\section{REFERENCES}

[1] Chon SH, Lee CB, Kim H, Chung WS, Kim YH. Diagnosis and prognosis of traumatic pulmonary psuedocysts: a review of 12 cases. Eur J Cardiothorac Surg 2006;29:819-23.

[2] Kato R, Horinouchi H, Maenaka Y. Traumatic pulmonary pseudocyst. Report of twelve cases. J Thorac Cardiovasc Surg 1989;97:309-12.

[3] Melloni G, Cremona G, Ciriaco P, Pansera M, Carretta A, Negri G, et al. Diagnosis and treatment of traumatic pulmonary pseudocysts. J Trauma 2003;54:737-43.

[4] Athanassiadi K, Gerazounis M, Kalantzi N, Kazakidis P, Fakou A, Kourousis D. Primary traumatic pulmonary 
pseudocysts: a rare entity. Eur J Cardiothorac Surg 2003;23:435.

[5] Luo L, Yin L, Liu Z, Xiang Z. Posttraumatic pulmonary pseudocyst: computed tomography findings and management in 33 patients. J Trauma Acute Care Surg 2012;73:1225-8.

[6] Tsitouridis I, Tsinoglou K, Tsandiridis C, Papastergiou C, Bintoudi A. Traumatic pulmonary pseudocysts: CT findings. J Thorac Imaging 2007;22:247-51.

[7] Cho HJ, Jeon YB, Ma DS, Lee JN, Chung M. Traumatic pulmonary pseudocysts after blunt chest trauma: Prevalence, mechanisms of injury, and computed tomography findings. $\mathrm{J}$ Trauma Acute Care Surg 2015;79:425-30.

[8] Hazer S, Orhan Soylemez UP. Clinical features, diagnosis, and treatment of traumatic pulmonary pseudocysts. Ulus Travma Acil Cerrahi Derg 2018;24:49-55.

[9] De A, Peden CJ, Nolan J. Traumatic pulmonary pseudocysts. Anaesthesia 2007;62:409-11.

[10] Celik B, Basoglu A. Posttraumatic pulmonary pseudocyst: a rare complication of blunt chest trauma. Thorac Cardiovasc Surg 2006;54:433-5. 